\title{
Legislação agrária em Rio Pardo oitocentista
}

\author{
Agrarian legislation in Rio Pardo nineteenth century \\ La legislación agraria en Rio Pardo siglo XIX
}

JoséAntonio Moraes do Nascimento*

\section{Resumo}

A sociedade agrária de Rio Pardo, na segunda metade do século XIX, era formada por vários grupos sociais de proprietários de terra, conforme consta dentre os declarantes no Registro Paroquial de Terras, determinado pela Lei de Terras de 1850. Apor intermédio desse expediente foi possível perceber a política de terras do governo imperial e analisar as relações sociais e econômicas (origem de novos povoadores, compra e venda de terras, relações de parentesco, casamento, vizinhança, apropriação de terras) e políticas (ocupação do poder e conflitos para conquistá-lo ou mantê-lo).

Palavras-chave: Relações de poder. Rio Pardo. Sociedade agrária.

\section{Introdução}

Sociedade agrária e relações de poder em Rio Pardo, na segunda metade do século XIX, tem a pretensão de identificar os grupos sociais de proprietários de terra declarantes no Registro Paroquial de Terras, determinado pela Lei de Terras de 1850, do município de Rio Pardo. Particularmente, pretende-se identificar os declarantes que utilizaram a nova legislação, sejam grandes, médios ou pequenos, bem como suas relações políticas, no âmbito local, provincial e imperial.

O conhecimento sobre as sociedades agrárias e suas relações de poder ainda ne-

\footnotetext{
* Doutor em História. Professor do Departamento de História e Geografia da Universidade de Santa Cruz, Brasil.
}

Recebido em 01/04/2016 - Aprovado em 01/09/2016

http://dx.doi.org/10.5335/hdtv.16n.2.6930 
cessita de mais estudos, principalmente os que apontem as questões pontuais das várias regiões. Neste texto será analisada a legislação agrária da segunda metade do século XIX para, na sequência do trabalho, observar-se sua influência e interferência em Rio Pardo. Pretende-se apresentar a política de terras do governo imperial, utilizando-se o Registro Paroquial de Terras, iniciado em 1854, naquela comuna. A partir disso, analisam-se as relações sociais e econômicas (origem de novos povoadores, compra e venda de terras, relações de parentesco, casamento, vizinhança, apropriação de terras) e políticas (ocupação do poder e conflitos para conquistá-lo ou mantê-lo).

Em linhas gerais, e a priori, pode-se afirmar que o poder público imperial fez uma intervenção no processo de apropriação da terra condicionada aos seus interesses. Inicialmente, foi elaborada e aprovada Lei de Terras, em 1850, e, na sequência, colocada em prática suas determinações, o que ocorreu de forma lenta e precária. Assim, o Registro Paroquial de Terras pode ser considerado como o primeiro censo geral sobre a propriedade rural do país, servindo também para identificar os habitantes (posseiros ou proprietários) que se estabeleceram na região, em áreas de campo e em áreas florestais. O registro, em conjunto com os testamentos, os inventários post-mortem e os autos de legitimação, permite visualizar a estrutura fundiária dos grupos sociais, as formas de organização do trabalho, a mobilidade social, a família, a herança e os conflitos. Nesse sentido, pretende-se identificar e situar esses declarantes nas suas relações econômicas, sociais e políticas em Rio Pardo.
Ao longo do século XIX, surgiram, na Província do Rio Grande do Sul, vários povoados, a maioria em função da intervenção e atuação do poder público no processo de ocupação, apropriação e povoamento. Assim, ocorreu a ampliação da apropriação das regiões florestais e o surgimento de vários aglomerados populacionais, alguns dos quais surgiram em função de projetos governamentais de colonização, envolvendo vários segmentos sociais e políticos interessados na efetiva colonização da região. Esse aumento populacional ocorreu com os migrantes e depois com os imigrantes e seus descendentes. O governo imperial desenvolveu programas e ações colonizadoras, pelo menos, desde o início do século XIX, com o objetivo de garantir uma ocupação rendosa para o Estado ou para as elites locais, com a comercialização das terras. O poder público somente interveio para evitar conflitos iminentes, ou seja, agiu para regularizar as áreas quando havia a necessidade de impedir a expansão dos conflitos.

Esses acontecimentos ligados à questão da ocupação e a apropriação da terra podem ser analisados com base na história agrária enquanto integrante da história social que, ao abordar acontecimentos, estruturas, comportamentos e relações entre grupos sociais, criam possibilidades para se descobrir as articulações entre o econômico, o político e o mental, estabelecendo os laços para entender uma sociedade, com sua estrutura econômica e social particular (CASTRO, 1997, p. 48).

Nesse sentido, 
[...] apesar de inúmeras imprecisões, é possível, a partir das declarações paroquiais, fazer um esboço do cadastro de terras de meados do século, destacando a forma de apropriação do solo, a relação jurídica, o valor, nomes dos proprietários, [...] limites e dimensões (LINHARES; SILVA, 1981, p. 94).

Por isso, será o documento principal a ser utilizados para compreender parte da política imperial de terras no Rio Grande do Sul. Além disso, para compreender a estrutura agrária faz-se necessário conhecer

[...] as formas de acesso ao solo e outros meios de produção (animais, instrumental agrícola, etc.) [...] já que são as bases das relações de produção na agricultura (CARDOSO, 1982, p. 39).

Essa atenção à história da região deve-se ao fato de que situações localizadas revelaram complexidades próprias, ou seja, ampliação da fronteira, contatos e conflitos entre as populações, que modificaram a paisagem e a organização social. Em síntese, deve-se conhecer os passos

[...] da fronteira agrícola que acompanhou [...] a ação dos homens na transformação da paisagem, os processos de adaptação e de transformação do meio físico e as formas de organização social daí resultantes (LINHARES, 1997, p. 173).

Além disso, a ação do poder público que influenciou e determinou relações econômicas e sociais. O privilégio dado à perspectiva mais ampla da história regional, concebida enquanto econômica e social, ocorre em função da possibilidade de apresentar situações localizadas que revelem complexidades próprias, sem, no entanto, perder de vista sua relação com o contexto mais amplo, do escravismo imperial.
Nesse sentido, pode-se afirmar que grande parte da província sul-rio-grandense esteve ocupada por grandes fazendas de criação e "industrialização" de gado e a agricultura colonial imigrante. Os lavradores nacionais ocupavam as terras florestais e eram homens livres, com pequenas posses, não havia se tornado grandes estancieiros e viviam da agricultura de subsistência. Dividiam o espaço agrário com os criadores de gado, grandes proprietários de terra e, a partir de meados do século XIX, com os imigrantes, principalmente alemães. Para compreender essa região e os grupos sociais que a integravam, a documentação a ser utilizada será aquela produzida pelos órgãos oficias, ou seja, os Registros Paroquiais de Terras, que permitem identificar alguns dos primeiros posseiros da região e o processo de ocupação bem como ter a relação daqueles que registraram suas terras e suas respectivas áreas.

O Livro Paroquial de Registro de Terras foi instituído pelo artigo $13^{\circ}$ da Lei de Terras, de 1850, e pelo Regulamento de 1854, particularmente nas determinações dos artigos 91 até o 107, que estabeleceram que se deveria fazer o registro das terras existentes em todo o país. Esses documentos tiveram valor legal de título de propriedade. O Registro Paroquial "pode ser considerado o primeiro censo geral sobre a propriedade rural do país" (ZARTH, 2002, p. 63), mesmo que, na maioria dos casos, não apresentasse o tamanho da área. Esse documento também servirá para identificar os habitantes, posseiros ou proprietários que se estabeleceram na região, tanto nas áreas de campo quanto, e principalmente, nas áreas florestais. O Registro Paroquial de Terras, em conjunto com 
os inventários post-mortem e os autos de legitimação, permitiram

[...] uma visão impressionante da estrutura fundiária dos grupos sociais, das formas de organização do trabalho, da mobilidade social e, enfim, da família, da herança e das fortunas (SILVA; LINHARES, 1995, p. 17).

Durante o período escravista, a plantation, no caso do Brasil, não foi uma unidade autossuficiente, pois havia áreas, em várias regiões, destinadas ao abastecimento interno, como foi o caso do Rio Grande do Sul, em que tropeiros e militares receberam terras da Coroa, cumprindo a função de ser uma atividade econômica diretamente relacionada à economia nacional, embora com dinâmica própria. Nesse sentido,

[...] a estrutura fundiária gaúcha foi marcada pela grande concentração de terras e de gado [...]. Essa estrutura, com a sua respectiva hierarquia [...], só conseguiria se reproduzir caso mantivesse um fluxo contínuo de vendas de gado para o mercado (FRAGOSO, 1998, p. 146).

Em geral, as regiões de fronteiras da província foram pensadas e construídas ideologicamente como local, por excelência, de terra ilimitada. Para facilitar a penetração nas matas, ao longo do século XIX, são abertas estradas ligando regiões distantes. Ao longo da estrada vão fixando-se moradores que garantiam a produção de subsistência. Assim também:

[...] quando da abertura do Caminho Novo para Minas, no final do século XVII, cresceu a circulação de mercadorias e homens entre a região de Minas Gerais e Rio de Janeiro. As terras localizadas ao longo do percurso começaram, então, a ser objeto de disputa. Pedidos de sesmarias e/ou desbravamen- tos tornaram-se recorrentes. Homens e mulheres provenientes de Minas ou do Rio de Janeiro desciam ou subiam o Caminho Novo em busca de uma parcela de terras, ainda em matas virgens, ocupadas por varias nações indígenas (MOTTA, 1998, p. 34).

A situação da região de Paraíba do Sul, no estado do Rio de Janeiro, demonstrou que, quando ocorreu o aumento populacional em função da contínua migração, mas também pela reprodução interna, como foi ao longo do século XIX, na Província do Rio Grande do Sul, os resultados foram famílias numerosas e disputas pela terra. Com vários filhos, a divisão dos bens foi maior, fragmentando terra, o que foi compensado com novas apropriações e um crescimento da população livre, principalmente onde o acesso à terra foi relativamente facilitado. Esses "homens livres pobres", pobres, mas não despossuídos como os escravos, ou "homens sem senhor", na denominação de Christopher Hill (1987), ao descrever o surgimento de uma camada de pessoas que não tinham mais vínculos com a sociedade feudal, na Inglaterra, tanto lá quanto aqui, dedicaram-se "ao suprimento de suas necessidades de subsistência" (CASTRO, 1987, p. 82).

Em Rio Pardo, também nesse contexto de região fronteiriça, o aumento populacional ocorreu ao longo do século XIX com uma migração constante. Antes disso, houve um primeiro momento, com uma ocupação militarizada que proporcionou o surgimento e aumento do povoado em torno de uma fortaleza, a Jesus-Maria-José. Um segundo momento, consolidou um núcleo urbano forte, com intensificação das atividades comerciais, que vai da primeira década do XIX até 
aproximadamente 1870. Ao mesmo tempo, ocorreu uma constante ocupação das regiões florestais, principalmente da região serrana, na qual é criado um núcleo de imigrantes alemães, que mais tarde vai dar origem ao município de Santa Cruz do Sul. Esses acontecimentos, de ocupação e aumento populacional de Rio Pardo, também foram regulamentados pela Lei de Terras e legislação subsequente.

\section{Alegislação de 1850 e a apropriação da terra}

A apropriação da terra, ou seja, sua transformação em propriedade e manutenção como tal, na segunda metade do século XIX, está relacionada, entre outros motivos, à Lei de Terras de 1850. O referido expediente legal permitiu que,

[...] cada terra em posse de cultura ou em campos de criação compreenderá, além do terreno aproveitado ou do necessário para pastagens dos animais que tiver o posseiro, outro tanto mais de terreno devoluto que houver contíguo, contando que em nenhum a extensão total de posse exceda a de uma sesmaria, para cultura ou criação, igual as últimas concedidas na mesma comarca ou nas mais vizinhas (IOTTI, 2001, p. 113).

Com a Lei de 1850, a terra devoluta poderia ser vendida pelo governo imperial, e não mais simplesmente ocupada.

Essa legislação compunha as reformas influenciadas pelas ideias liberais que chegaram até a América Latina por

[...] uma primeira geração de latino-americanos pós-independência. Grande parte havia estudado na Europa e estavam familiarizados com as ideias liberais então imperantes (LINHARES; SILVA, 1999, p. 61).
Em geral, a primeira metade dos oitocentos foi marcada pela influência e reformas liberais, que orientaram para um novo tipo de apropriação da terra. Essas ações atingiram principalmente regiões que eram importantes centros administrativos e colônias, onde havia grandes áreas consideradas devolutas. Assim, as propriedades

[...] comunais, depois de liberadas pelas reformas, foram transformadas em latifúndio muitas vezes tão retrógrados quanto as terras em mãos dos grupos conservadores e a ideia de formação de colônias agrícolas e médias propriedades mais produtivas tornou-se letra morta (WASSERMAN, 2000, p. 199).

O contexto anterior à aprovação Lei de Terras é marcado:

[...] pelo desenvolvimento acelerado do setor primário-exportador devido ao desenvolvimento das forças produtivas, à firme intervenção do Estado na economia e à recuperação europeia, que reativou a demanda por produtos primários em níveis superiores ou equivalentes aos anos que antecederam às Independências (WASSERMAN, 2000, p. 185).

Em função disso, desencadeou-se um otimismo:

[...] para uma geração nova, jovens das elites provinciais que pensavam na possibilidade de romper com os restos das instituições coloniais e retomar os ideais reformistas dos liberais do início do século. A partir de 1850, esses liberais mostraram-se mais radicais e decididos do que os do passado, talvez porque a conjuntura social e econômica lhes fosse mais favorável para a realização das reformas (WASSERMAN, 2000, p. 185). 
A ocupação territorial configurou-se com maior ênfase com a concessão de sesmarias até 1822 e, após este período, com as concessões de posses. Após a aprovação da lei, as terras passam a ser vendidas. Em

[...] 1822 tivemos a proibição da concessão de sesmarias. Esta proibição permaneceria até a Lei de Terras do ano de 1850. Então, entre os anos de 1822 e 1850, a única forma de acesso legal à terra era a posse (VIAL, 2003, p. 178).

A própria constituição de 1824, a primeira do Brasil, garantia privilégios e direitos aos cidadãos. Entretanto, "ser cidadão, em 1824, significava ser proprietário que, por sua vez, era proprietário de terras" (2003, p. 178).

Em linhas gerais, a Lei de Terras, que foi aprovada no contexto da proibição internacional do comércio de negros, em um crescente movimento de liberação dos escravos (espontânea ou forçada pelas fugas, pois as matas poderiam ser um local apropriado para residir) e com a vinda de imigrantes livres para o Brasil, proibiu a aquisição de terras, a não ser pela compra. Impedia-se a posse por parte dessa população, pois, na argumentação de José de Souza Martins, "num regime de terras livres o trabalho tinha que ser cativo, num regime de trabalho livre a terra tinha que ser cativa" (MARTINS, 1981, p. 32). Ou seja, as leis surgem no contexto social que estão inseridas e

[...] o sistema jurídico daqueles anos era o reflexo do sistema econômico. Em outras palavras, só tinha acesso ao sistema de direito quem também já tinha assegurado o acesso ao sistema da economia (VIAL, 2003, p. 179).
Dessa forma, a legislação de meados dos oitocentos pode ser pensada como um instrumento de controle da propriedade para impedir e limitar o livre acesso ao solo pelos colonos imigrantes e pequenos agricultores nacionais. Foi uma "legislação criada por uma elite escravista para administrar a superação da escravidão" (FRAGOSO, 2000, p. 147). Inicialmente, a ideia da posse poderia favorecer o lavrador sem recursos, mas, na prática, não foi o que ocorreu na maioria dos casos onde se instaurou a grande propriedade.

Essas concepções, estabelecidas pela legislação agrária de 1850, são semelhantes ao que ocorreu na Inglaterra, no século XVII. Nesse caso, para solucionar o problema da fome defendeu-se a ideia de que

[...] seria possível produzir mais alimento caso as vastas áreas preservadas como florestas reais fossem abertas ao cultivo, se os terrenos comunais e ociosos fossem arados, se os pântanos e charcos fossem drenados (HILL, 1988, p. 17).

Tanto os pequenos ocupantes quanto os squatters (ocupantes sem título da terra, que se fixavam nos limites das propriedades e usurpavam os bens comunais), os cottagers (trabalhadores agrícolas somente posseiros, sem direito à moradia):

[...] e todos aqueles que detinham direitos comuns perderiam prerrogativas valiosas se florestas, pântanos e terrenos comunais fossem cercados e entregues à propriedade privada: o direito de apascentar os próprios animais, caçar e se abastecer de combustível. Foi exatamente por esse motivo que Francis Bacon aconselhou Jaime I a manter o controle sobre as terras ociosas e comunais reais, fontes potenciais de rique- 
za no caso de serem cercadas e melhoradas. Durante toda a primeira metade do século os senhores de terras, decididos a levantar cercas, lutaram contra os cottagers e squatters, alegando seus direitos sobre os terrenos comunais e pântanos. A Coroa apôs-se àqueles que invadiam as florestas reais. $\mathrm{O}$ governo multava esporadicamente os que levantavam cercas, mas pouco fez no sentido de proteger as vitimas desse ato. Ele próprio possuía terras que mandava cercar (HILL, 1988, p. 17-18).

\section{Isso provocou reação, e os revoltosos}

[...] exigiam que todas as terras e florestas da Coroa, os terrenos comunais e ociosos fossem cultivados pelos pobres, através da posse comunitária, e que a compra e venda da terra deveria ser proibida por lei (HILL, 1988, p. 17-18).

Esses fatos culminaram, juntamente com outros, na Revolução Inglesa de 1640, sob a liderança de Oliver Cromwell. Ou seja, a terra era uma mercadoria em potencial, que poderia render lucro aos proprietários que conseguissem comprovar a propriedade (legal ou ilegalmente), mas também para Coroa, que queria manter o controle sobre essas terras. Procedimento semelhante ao que ocorreu no Brasil, ao ser instituído a lei de 1850.

Como a Lei de Terras objetivava definir o que era de domínio privado do que não era, buscou regularizar situações anteriores. Até a independência do Brasil,

[...] possuir terras dependia única e exclusivamente da vontade do rei, agora bastava ter dinheiro para adquiri-las [...] O problema é que só havia dinheiro para adquirir a propriedade da terra quem já tivesse a terra e desta gerado algum lucro e acumulado dinheiro para adquiri-la (VIAL, 2003, p. 181).

Portanto:
[...] a única possibilidade de aquisição de terras foi através da compra. As formas tradicionais utilizadas, até então, de doação ou ocupação, não eram mais possíveis sob a perspectiva jurídica. Ainda de um ponto de vista jurídico, a Lei de Terras dificultou quem, anteriormente, considerava-se proprietário de determinada porção de terras e que ainda não havia sido regulada até 1850. Para obter o titulo jurídico de proprietário, teve que se submeter ao controle burocrático do governo brasileiro que, para tal, criou a Repartição Geral das Terras Públicas. Esta 'Repartição' tinha como função dificultar a vida de novos possíveis latifundiários, sendo que, para tal, o tamanho da posse não poderia ser maior do que a maior doação feita no distrito em que se localizava (2003, p. 182).

Nesse sentido, o ministro conservador Joaquim José Rodrigues Torres, quando se discutia a Lei de Terras, deixou claro que se queria

[...] impedir que os trabalhadores que chegam de outras partes do mundo possam vir ao Brasil e em lugar de trabalhar para o proprietário, pelo menos certo tempo [...] ocupem terras da Coroa imediatamente (LINHARES; SILVA, 1981, p. 34).

Assim, o projeto do Partido Conservador, que contemplou os interesses e a pressão dos liberais, foi aprovado legitimando-se as posses e sesmarias de antes de 1850, como desejavam os posseiros fluminenses, paulistas e mineiros, que exigiram um programa liberal com:

[...] uma lei de terras e uma firme política imigracionista [...] Suas terras não tinham origem nas antigas sesmarias, mas na tomada pura e simples de terras devolutas. Fazia-se necessário regularizar uma situação que já beirava a violência e, simultaneamente, fechar a porta pela qual estes mesmos homens passaram (LINHARES; SILVA, 1981, p. 32). 
A maioria dos grandes proprietários era de posseiros que se tornaram proprietários embasados pela Lei de Terras. Por sua vez, os trabalhadores nacionais pobres, também chamados de caboclos, não tiveram condições de legalizar suas posses ou foram coagidos a deixar a terra. Entretanto, Márcia Motta, ao realizar essa discussão, afirmou que:

[...] é verdade que a maior parte dos posseiros era, de fato, grandes fazendeiros muitos deles com prestigio e poder em sua localidade. Mas também é verdade que havia um sem-número de pequenos posseiros que poderiam se beneficiar com a nova lei. Assim, em certo sentido, ela abria uma brecha no processo de concentração fundiária em curso, permitindo uma possibilidade de democratizar o acesso à terra, ao salvaguardar os interesses dos lavradores que haviam ocupado pequenas parcelas de terras, antes da aprovação da lei (1998, p. 142).

A lei determinou um valor a ser pago para a legitimação das terras, mas, ao mesmo tempo, em circular de 10 de abril de 1858, a Coroa apontou para a possibilidade de atender aos pobres que não poderiam:

[...] arcar com as despesas exigidas para a legitimação de suas posses, principalmente as de 'muita pequena extensão e de valor que não chega a importância das ditas despesas' e resolveu 'que o juiz comissário que tiver de proceder à medição para as legitimações das referidas posses, quando reconhecer que estas não excedem a área de 250.000 quadradas, e que os respectivos posseiros não têm meios para satisfazer as despesas (MOTTA, 1998, p. 142-143).

Se o presidente da província concordasse com o juiz, era feita a medição e legitimação por conta do governo. Para justificar seu entendimento, a autora citou o caso de um pequeno posseiro que aplicou a Lei de Terras para reivindicar sua posse. Concluiu, afirmando que:

[...] se é obviamente impossível traduzir as reais intenções de Antonio Pascoal ao referir-se a Lei de Terras de 1850, não é difícil imaginar que ele sabia que ela postulava como uma de suas atribuições, a legitimação das terras devolutas ocupadas por posse. Assim, ao se referir à Lei de Terras, Antonio Pascoal procurava utilizá-la como argumento jurídico a seu favor (MOTTA, 1998, p. 193).

Nesse sentido, a conclusão de Márcia Motta e de Cristiano Christillino, de que "não foram apenas os grandes fazendeiros que se utilizaram da Lei, os pequenos posseiros também se valeram da mesma em seus litígios" (CHRISTILLINO, 2004, p. 67), é pertinente em termos teóricos, entretanto, discutível para o contexto geral nacional. Quando a lei de 1850 foi elaborada, não foi para um ou outro grupo específico, mas para todos os cidadãos e a questão fundamental a ser considerada foi quem obteve os maiores benefícios. Em algumas regiões, como demonstrou Márcia Motta (1998) e Luís Augusto Farinatti (1999), nos seus respectivos estudos, foram os trabalhadores nacionais que obtiveram os maiores ganhos com a referida lei. Entretanto, não foi o que normalmente aconteceu, permanecendo válida a afirmação de José de Souza (MARTINS, 1981, p. 32). Como Cristiano Christillino afirmou, a lei fez parte de um arsenal jurídico que poderia ser utilizado tanto pelos grandes quanto pelos pequenos posseiros (CHRISTILLINO, 2004), embora isso não signifique que ambos a tenham aplicado em seu benefício. 
Uma discussão realizada por Marc Bloch, referindo-se à França, é elucidativa para se compreender essa diversidade do meio rural, também do Brasil. Segundo ele, "a sociedade camponesa comporta classes sociais muito distintas [...]. Tipos diferentes, respondendo a condições de vida diferentes, coexistindo frequentemente" (BLOCH, 2001, p. 195). Assim sendo, os cercamentos na França do século XVIII eram, praticamente:

impossíveis para os pequenos camponeses [...], mas não impossíveis para os senhores. É preciso não esquecer que o domínio dos senhores era menos fracionado e que alguns entre eles tinham feito esforço, há muito tempo, para concentrá-lo... De outro lado, eles tinham recursos que faltavam aos modestos proprietários (BLOCH, 2001, p. 267).

Nessa perspectiva, Motta, ao referir-se a um conflito entre um pequeno posseiro e um grande proprietário que tentava incorporar a posse entre suas terras, na região de Paraíba do Sul, no Rio de Janeiro, afirmou que, quando os conflitos ocorriam entre sujeitos sociais desiguais:

[...] os fazendeiros mostram todas as facetas de seu poder, atuando como uma das partes ou como testemunhas do próprio conflito. Nos embates entre fazendeiros e pequenos posseiros [...] a questão da existência de matas virgens ou da realização de atos possessórios torna-se efetivamente importante e serve de ponto de partida para uma discussão sobre o direito à terra [...]. O direito à terra - o direito destas categorias sociais de ocupar terras devolutas - foi sendo dificultado e impedido pela ação de fazendeiros que forjavam, nos processos, a inexistência de matas virgens, incorporando-as às suas grandes glebas de terras (1998, p. 74).
Assim, os "pobres, poderiam, em tese, reivindicar a propriedade efetiva de suas posses, porém o processo de legitimação das posses era difícil para esses" (ZARTH, 2002, p. 91), pois implicava recursos financeiros, além de um longo processo jurídico para a obtenção do título das terras. A ação iniciava-se com o:

[...] registro paroquial de terras, em seguida era requerida a legitimação da área, a qual consistia num longo processo que envolvia a comprovação de ocupação por posse ou título de concessão e a medição da área e, em muitos casos, a resolução de ações de embargo promovidas pelos confrontantes, além de vários outros trâmites burocráticos. Terminado o processo era então concedido o título de propriedade (CHRISTILLINO, 2004, p. 59).

Nesse sentido, para os fazendeiros a ocupação das terras devolutas e sua incorporação aos seus domínios compunha a visão de que ser senhor de terra implicava em poder expandi-la sem se submeter a nenhuma determinação de terceiros. Já os pequenos posseiros baseavam-se em uma tradição de legitimidade da primeira ocupação como forma de aquisição.

A documentação apontou que os pequenos posseiros tinham, legalmente, direito ao acesso à terra, pois era:

[...] considerado legítimo que a terra apossada fosse efetivamente aquela onde haviam sido feitos atos possessórios. Assim, os limites entre fazendas e sítios deveriam se dar nas fronteiras das culturas efetivas, práticas agrícolas demonstrativas de ocupação. Neste mesmo sentido, as áreas com matas virgens, terras ainda devolutas, poderiam pertencer àquele que ali fizera em primeiro lugar atos possessórios. Em pequenas parcelas de terras, homens com poucos recursos plantavam pequenas ro- 
ças de alimentos e construíam a suas choupanas. Mas este mesmo território era cobiçado por fazendeiros [...] que buscavam expandir os seus domínios e, muitas vezes, negavam, pela prática da expulsão, as parcelas de terras, antes pertencentes aos pequenos posseiros (MOTTA, 1998, p. 110).

Ao longo da história do Brasil houve preocupação do poder público na demarcação e medição das terras. As sesmarias já exigiam cultura efetiva das terras e, em 1795, também havia um alvará da Coroa determinando essa regulamentação de ocupação da terra. Entretanto:

[...] as medições e demarcações feriam os interesses dos grandes fazendeiros, fazendo com que eles insistissem em descumprir as Ordens Reais. A Coroa procurava controlar o acesso à terra, não somente legislando acerca da sua ocupação, mas esforçando-se em fiscalizar o cumprimento de suas exigências (MOTTA, 1998, p. 37-38).

No entanto, os fazendeiros agiam com uma lógica própria, de senhores e possuidores de terras, que:

[...] implicava a capacidade de exercer o domínio sobre as suas terras e sobre os homens que ali cultivavam (escravos, moradores e arrendatários). Implicava ser reconhecido pelos seus vizinhos como um confrontante. E relacionava-se também à possibilidade de expandir suas terras para além das fronteiras originais, ocupando terras devolutas ou apossando-se de áreas antes ocupadas por outrem. O que importava, pois, para os fazendeiros não era a medição e demarcação tal como a desejavam os legisladores. Medir e demarcar, seguindo as exigências da legislação sobre as sesmarias, significava, para os sesmeiros, submeter-se à imposição de um limite a sua expansão territorial (MOTTA, 1998, p. 38).
Muitos conflitos tiveram origem na ambiguidade da própria lei e na indefinição de sua aplicação, justamente porque havia o objetivo de atender ao interesse dos vários grupos que disputavam a posse ou a propriedade da terra. Em termos de política provincial, a Lei de Terras, mais particularmente o regulamento de 1854 , no seu artigo 33, facultou o direito ao presidente da província de prorrogar o prazo para realizar as medições das posses, mecanismo amplamente utilizado (OFÍCIO, 1867).

O regulamento de 1854 determinou que se deveria fazer a medição e revalidação das sesmarias ou a legitimação de posses realizadas antes de 1850. A Repartição Geral de Terras Públicas foi responsabilizada para tal, mas somente após 1860 teve condições de realizar o trabalho com mais eficiência, ainda assim de forma lenta. O regulamento, mesmo conferindo um grande poder à esfera local, ou seja, ao juiz comissário, subordinado à Repartição Especial de Terras Públicas de cada província, garantiu a decisão final ao governo central. Quando houvesse conflito de terras entre posseiros, o juiz comissário era o primeiro a julgar a questão, assim como era o avaliador dos bens, em caso de necessidade. Além disso, ele também podia "ser conivente com a incorporação de [...] pequenas posses por outros requerentes, com base no seu poder pessoal e político" (CHRISTILLINO, 2004, p. 84). O juiz comissário, o fiscal, o diretor e o inspetor da repartição compunham a burocracia estatal com grandes poderes (IOTTI, 2001, p. 120, 124-125), sendo que os dois primeiros eram os que mantinham contato direto com os posseiros. O delegado da repartição apre- 
sentava a decisão final que, geralmente, era a posição da presidência, cabendo, em caso de discordância, reclamação ao Ministério da Agricultura. O presidente da província era quem nomeava os juízes, fiscais, delegados e diretores, reforçando seu poder e "em suas ações sobre os processos de legitimações, estavam direcionadas no sentido de alargar e reforçar as redes de aliança em torno do Estado" (CHRISTILLINO, 2004, p. 89).

Ainda, pelo artigo 87, ficou estabelecido que os juízes municipais seriam os responsáveis pela conservação das terras devolutas, devendo proceder contra quem cometesse delitos. Assim, "ao relegar aos juízes municipais a conservação das suas terras, o Estado estava entregando aos 'proprietários' locais o controle sobre" (CHRISTILLINO, 2004, p. 101) terras públicas e, consequentemente, sobre sua comercialização. $\mathrm{O}$ artigo 42 do regulamento determinava que os posseiros que não comprovassem sua posse e que a ocupassem desde antes de 1850 receberiam uma indenização pelas benfeitorias, mas se não a aceitassem, seriam despejados. Assim,

[...] uma vez que o Regulamento abria brechas para as pequenas posses anteriores a Lei de Terras, irá, no entanto, transformar as ocupações dos lavradores nacionais, a partir desta, em crime (CHRISTILLINO, 2004, p. 108).

A Lei de Terras de 1850 passou a ser a principal legislação a regulamentar a ocupação da terra no país. Não foi diferente em Rio Pardo. Como havia muitas áreas ocupadas por sesmarias, outras simplesmente apossadas e outras ainda, devolutas, a nova lei foi norteadora das transformações das posses em propriedades. No entanto, não foi um processo totalmente pacífico tendo, em muitos casos, grandes conflitos. $\mathrm{Na}$ sequência, serão apresentados alguns elementos desse processo em Rio Pardo, pós 1850.

\section{Freguesia de Nossa Senhora do Rosário da Cidade de Rio Pardo}

Os limites do Rio Grande do Sul foram estabelecidos a partir da conquistada do território por estancieiros militares no início do século XIX, em um processo de ocupação de grandes extensões de terra na região de fronteira entre as colônias espanholas, depois países platinos, e a colônia portuguesa. Por esse motivo, foi uma ocupação militarizada, privilegiando a lógica de que garantir a fronteira significava ampliar e/ ou conservar o território. Nesse sentido, o governo, como recompensa aos executores dessa tarefa, distribuiu grandes extensões de terra, tornando-os, além de chefes militares, grandes estancieiros de criação e comércio de gado. Áreas que, a partir da Lei de Terras, deveriam ser declaradas e realizadas os respectivos encaminhamentos que determinava a nova legislação. Estabeleceram-se assim, com a doação de sesmarias e com a expansão da pecuária, os marcos originais da formação da estrutura agrária sul-rio-grandense. Conhecer como ocorreu esse processo em Rio Pardo, em meados dos oitocentos, é o que se pretende com o presente texto, tendo como base documental o Registro Paroquial de Terras daquele município.

O sul do Brasil, particularmente o Rio Grande do Sul, apenas no século XVIII recebeu efetiva atenção da Coroa portuguesa em 
função de objetivos geopolíticos, pois "era a porta de entrada natural para um possível ataque castelhano ao Brasil" (ZARTH, 2002, p. 50). A partir de 1756 ocorreu a ocupação luso-brasileira, transformando os campos missioneiros em estancias privadas, e o gado passou a ser "a riqueza que viabilizou economicamente a ocupação europeia [...] e deu origem a uma poderosa classe de latifundiários dedicados à pecuária" (ZARTH, 2002, p. 51). Os primeiros núcleos de atividade produtiva empreendida pelos portugueses, no Rio Grande do Sul, foi a partir das estâncias de criação de gado, também com o objetivo de estabelecer as fronteiras. Nesse sentido, "a ocupação da fronteira de Rio Pardo está diretamente vinculada à concessão de sesmarias para a atividade criatória" (SPENNER, 2013, p. 74).

Assim, em 1809, quando da sua criação, Rio Pardo representava mais da metade do território da capitania, com uma área de $156.803 \mathrm{~km}^{2}$ (REZENDE, 1987), seu território era a fronteira portuguesa com as terras castelhanas. A Câmara Municipal de Rio Pardo foi instalada em 1811 e, juntamente com Porto Alegre, Rio Grande e Santo Antônio da Patrulha, integrou os primeiros municípios da Capitania de São Pedro. Em função de seu porto, Rio Pardo recebia grande número de pessoas que vinham buscar ou trazer mercadorias, transportados principalmente pelo Rio Jacuí, percorrido por embarcações que traziam produtos de Porto Alegre para serem distribuídos por terra para a serra e a fronteira ou que os levava rio abaixo para o comércio com outras regiões.

Como Rio Pardo passou a fazer parte do domínio português pelo Tratado de Ma- dri, em 1750, a preocupação era garantir a posse do território. Assim, a Coroa portuguesa passou a gratificar os oficiais e praças que serviam em Rio Pardo dando-lhes sesmarias. Nesse sentido, a

[...] palavra sesmaria tomou caráter de medida agrária, equivalente a uma légua de frente por três de fundo (cerca de 13.000 ha), o que significa que era comum a posse de áreas com essas dimensões (ZARTH, 2002, p. 61).

Os sesmeiros, em Rio Pardo, deveriam ocupar imediatamente as terras e constituir morada, com mangueiras e plantações. Conforme Rezende (1987), em função disso várias famílias, com seus escravos, trocaram o povoado para ocupar suas posses e criar estâncias no meio rural. Dessa maneira,

[...] o Município de Rio Pardo caracteriza-se por ter sido formado a partir de motivos militares. Ou seja, os militares e suas famílias que vieram para ocupar a fortaleza (Jesus-Maria-José) acabaram formando o seu primeiro núcleo populacional (SPENNER, 2013, p. 76).

Em toda a província, e Rio Pardo não fugiu à regra,

[...] as áreas de terras apropriadas pelos militares e civis eram, preferencialmente, de campo nativo, nas quais estabeleciam suas estancias pastoris (ZARTH, 2002, p. 61).

A partir de 1809, até aproximadamente 1865, iniciou-se um período de grande desenvolvimento do comércio, o que permitiu que Rio Pardo passasse da condição de vila à categoria de cidade, com toda sua organização política, administrativa e judiciária. Ao mesmo tempo, com todos esses elementos se interinfluenciando, o núcleo urbano cresceu. 
A Tabela 1 apresenta a população e a densidade populacional de Rio Pardo, em comparação com outros municípios, em 1859:

Tabela 1 - Densidade demográfica - 1859

\begin{tabular}{l|r|r|r}
\hline \multicolumn{3}{c}{ Densidade demográfica em 1859} \\
\hline Município & População & Área $\left(\mathrm{km}^{2}\right)$ & $\begin{array}{r}\text { Densidade } \\
\left(\mathrm{hab} / \mathrm{km}^{2}\right)\end{array}$ \\
\hline Porto Alegre & 29.723 & 4.325 & 6,87 \\
Rio Pardo & 18.322 & 8.809 & 2,69 \\
Bagé & 12.342 & 13.500 & 0,91 \\
Cruz Alta & 34.692 & 50.030 & 0,69 \\
\hline
\end{tabular}

Fonte: Fundação de Economia e Estatística Siegfried Emanuel Heuser (1981).

Comparando-se com os dados de 1900 (Tabela 2), Rio Pardo aumenta a população e diminui a área, o que, consequentemente, vai aumentar a densidade demográfica, como segue:

Tabela 2 - Densidade demográfica - 1900

\begin{tabular}{l|r|r|r}
\hline \multicolumn{4}{|c}{ Densidade demográfica em 1900} \\
\hline \multicolumn{1}{c|}{ Município } & População & Área $\left(\mathrm{km}^{2}\right)$ & $\begin{array}{r}\text { Densidade } \\
(\text { hab./km²) }\end{array}$ \\
\hline Porto Alegre & 73.674 & 2.219 & 33,20 \\
São Leopoldo & 28.812 & 1.263 & 22,81 \\
Rio Pardo & 22.478 & 3.645 & 6,17 \\
Santa Cruz & 9.054 & 1.989 & 11,64 \\
Bagé & 28.956 & 7.107 & 4,07 \\
Cruz Alta & 23.671 & 7.303 & 3,24 \\
\hline
\end{tabular}

Fonte: Fundação de Economia e Estatística Siegfried Emanuel Heuser (1981).

Alguns elementos novos mudaram a configuração populacional e territorial de Rio Pardo, particularmente, em meados do século XIX, quando um núcleo com coloni- zação de imigrantes alemães instalou-se em pequenas propriedades, em regime de trabalho familiar. Estabeleceram-se em duas colônias oficiais (Santa Cruz e Monte Alterne), além de algumas particulares, dentre as quais se destacam: Cerro Alegre, Rincão Del Rey, Germânia, Melos, Rio Paraense, Faxinal de Dentro, Entre-os, Formosa, Trombudo, Chaves, Linha João Alves e Pinheiral (VOGT, 2001). Dessa forma, a partir do século XIX, Rio Pardo

[...] tornou-se, igualmente, centro de produção agrícola e seu porto fluvial um movimentado entreposto de comércio. Após diversas emancipações, o Município de Rio Pardo acabou perdendo território, o que afetou diretamente a sua economia (SPENNER, 2013, p. 78).

Como já exposto anteriormente, a ocupação inicial foi com concessão de sesmarias, justamente para povoar um território que anteriormente pertencia à Espanha. Por isso,

[...] as terras concedidas nos tempos iniciais constituíam-se de áreas de campo onde a atividade criatória se desenvolvia quase que naturalmente, havendo pouca interferência do homem. Já as áreas cobertas por espessas florestas e que não se prestavam à atividade criatória foram desprezadas inicialmente (SPENNER, 2013, p. 79).

Em função disso, na década de 1860, havia algumas poucas estâncias em Rio Pardo com mais de 30 mil hectares que acabavam concentrando extensões significativas do território do município. Tanto o Registro Paroquial de Terras (REGISTRO, 1854-1856), quanto o Conde d'Eu, que esteve em Rio Pardo, em 1865, confirmam essa concentração das terras. Segundo o conde, 
[...] quarenta léguas quadradas que se estendem em volta de Rio Pardo pertencem somente a quatro proprietários, devendo notar-se que dois deles são cunhados que entre si partilharam a herança de seu sogro; mas estes já encontraram meio de comprar as terras dos outros dois. Estas enormes propriedades são aplicadas à criação de gabo bovino e cavalar [...] sobretudo do primeiro, que se transforma em carne seca e em couros, para a exportação ( $\mathrm{D}^{\prime} \mathrm{EU}$, 1981, p. 38).

Dentre esses estancieiros, destacam-se Mathias José Velho (INVENTÁRIO, 1876) e José Ferreira Porto (INVENTÁRIO, 1882). O primeiro era proprietário de uma área denominada Estância da Vitória. Faleceu em 25 de maio de 1875 e seu inventário post mortem foi iniciado em 8 de março de 1876 e concluído em 1879. Já José Ferreira Porto era proprietário da Estância das Pederneiras e faleceu em 29 de dezembro de 1881, sendo inventariado entre 1882 e 1884.

Mathias José Velho, proprietário da Estância Santa Vitória (também conhecida como Estância da Vitória), que se localizava às margens do Rio Jacuí, hoje entre Rio Pardo e Pantano Grande. A área havia sido comprada de Pedro Rodrigues Chaves, em 29 de dezembro de 1857 e denominava-se Estância Nossa Senhora da Vitória. Pedro Rodrigues Chaves, desde 1855, Barão de Quaraí, era senador do Império e presidente da Província da Paraíba, faleceu em 1866, na Itália. Em função do título de seu antigo proprietário, a propriedade também foi conhecida como Estância do Barão de Quaraí. Sua área de 8 léguas de campo equivalem a 35.216 hectares e tinha por limites o Rio Jacuí e os arroios Capivari, Dom Marco e Tabatingai (INVENTÁRIO, 1876). Ou seja,
[...] nos dias atuais elas compreendem toda a extensão da rodovia BR 471, após a ponte do Rio Jacuí até a cidade de Pântano Grande, um percurso de cerca de 25 quilômetros (SPENNER, 2013, p. 83).

Portanto, Mathias José Velho era um homem de muitas posses rurais e urbanas, um dos mais ricos de toda a província na segunda metade do século XIX, conforme demonstrou seu inventário post mortem. Nascera em Mostardas, em 1792 e morreu em Rio Pardo, em 1875. Casou-se com Luciana Francisca da Terra, em 1827, e o casal teve onze filhos. Conforme o inventário, a Estância da Vitória compunha-se de:

[...] uma estância de criar, denominada de Nossa Senhora da Vitória na margem direita do rio Jacuí fronteira nesta cidade onde residia o inventariado Mathias José Velho e reside a viúva inventariante, contem oito léguas de campo e seis com matos, com todas as propriedades, pomares, e bem feitorias existentes no mesmo campo que os avaliadores avaliaram em trezentos e vinte contos de réis (320:000\$000). Todos animais da estância no valor: 196:410\$0950. Móveis no valor 4:187\$3010 (INVENTÁRIO, 1876).

O inventário apresenta também uma descrição detalhada de todo o patrimônio de Mathias José Velho, disperso por várias regiões da província. Na Estância da Vitória, em 1876, havia 15.032 animais, um número elevado para a época. Consequentemente, "para um rebanho desse porte, era necessária uma boa extensão de terra, e isto não era problema para a propriedade, já que possuía 34.848 hectares" (SPENNER, 2013, p. 93). Além disso, o Barão do Quaraí vendera a Mathias Velho a Estância com cinquenta escravos (RIO GRANDE DO SUL, 2010, p. 238). 
Outro estancieiro que se destacou em Rio Pardo foi José Ferreira Porto (INVENTÁRIO, 1882), proprietário da Estância das Pederneiras que, no final do século XIX, estava localizada em Capivary, quinto distrito de Rio Pardo, próxima às margens do Rio Jacuí e da estrada Passo das Pederneiras. A área atualmente faz parte do município de Pantano Grande. Em 1882, a estância perfazia um total de 8 léguas de campo, ou seja, aproximadamente 35 mil hectares (INVENTÁRIO, 1882). Os limites da área ficavam, ao norte, com o Rio Jacuí e, ao leste, fazia divisa com os herdeiros de José Mathias Velho. A família Ferreira Porto comprou a estância dos herdeiros do português Francisco Veloso Rebelo, que a comprara, em 1780, de "três possuidores: Bernardo Soares, José Soares e Ten. Manuel Caio e Sousa" (MACEDO, 1969, p. 117). Em geral, os ocupantes de terras, em Rio Pardo, eram militares, mas também havia tropeiros, comerciantes e imigrantes alemães que desenvolveram a agricultura.

Esses dados demonstram que a ocupação se deu, na maioria do território, em grandes áreas. Uma questão ainda em aberto é até que ponto pequenos posseiros fizeram uso da lei de 1850 para se tornar proprietários e verificar se de fato conseguiram a propriedade da terra, visto que havia custos para a medição e legitimação. Somente futuras pesquisas poderão elucidar tais questões, que é o objetivo da sequência desse trabalho. De qualquer forma, pode-se afirmar que a sociedade agrária de Rio Pardo era formada por diferentes grupos sociais de proprietários, inclusive por imigrantes alemães.
Abstract

The agrarian society of Rio Pardo, in the second half of the nineteenth century, was formed by various social groups of landowners, as recorded among respondents in the Parish Register of Lands, determined by the Land Law of 1850 . Through this expedient was possible to see the Imperial Government land policy and analyze the social and economic relations (source of new settlers, purchase and sale of land, kinship, marriage, neighborhood, land ownership), and political (power occupation and conflict to win him or keep it).

Keywords: Power relations. Rio Pardo. Agrarian society.

\section{Resumen}

La sociedad agraria de Río Pardo, en la segunda mitad del siglo XIX, fue formada por diversos grupos sociales de los propietarios de tierras, como se registra entre los encuestados en el Registro Parroquial de Tierras, determinado por la Ley del Suelo de 1850. A través de este recurso era posible ver la política de tierras del Gobierno Imperial y analizar las relaciones sociales y económicas (fuente de nuevos colonos, compra y venta de tierras, el parentesco, el matrimonio, el vecindario, la propiedad de la tierra), y político (ocupación poder y conflicto de ganarlo o guardarlo).

Palabras clave: Las relaciones de poder. Río Pardo. Sociedad agraria. 


\section{Referências}

BLOCH, Marc. A terra e seus homens: agricultura e vida rural nos séculos XVII e XVIII. Bauru: Edusc, 2001.

CARDOSO, Ciro Flamarion. Agricultura, escravidão e capitalismo. Petrópolis: Vozes, 1982.

CASTRO, Hebe. História social In: CARDOSO, Ciro; VAINFAS, Ronaldo (Org.). Domínios da história. Rio de Janeiro: Campus, 1997.

CASTRO, Hebe Maria Mattos de. Ao sul da história: lavradores pobres na crise do trabalho escravo. São Paulo: Brasiliense, 1987.

CHRISTILLINO, Cristiano Luís. Estranhos em seu próprio chão: o processo de apropriações e expropriações de terras na província de São Pedro do Rio Grande do Sul (o Vale do Taquari no período de 1840-1889). Dissertação (Mestrado em História) - Universidade do Vale do Rio dos Sinos, São Leopoldo, 2004.

D’EU, Gastão de Orléans. Viagem militar ao Rio Grande do Sul. Belo Horizonte: Itatiaia; 1981.

FARINATTI, Luís Augusto Ebling. Sobre as cinzas da mata virgem: lavradores nacionais na Província do Rio Grande do Sul (Santa Maria 1845-1880). Dissertação (Mestrado em História do Brasil) - Pontifícia Universidade Católica do Rio Grande do Sul, Porto Alegre, 1999.

FRAGOSO, João Luis Ribeiro. Homens de grossa aventura: acumulação e hierarquia na praça mercantil do Rio de Janeiro (1790-1830). 2. ed. Rio de Janeiro: Civilização Brasileira, 1998.

FRAGOSO, João Luís. O Império Escravista e a República dos Plantadores. In: LINHARES, Maria Yedda Leite (Org.). História geral do Brasil. 9. ed., atual. Rio de Janeiro: Campus, 2000.

FUNDAÇÃO DE ECONOMIA E ESTATÍSTICA SIEGFRIED EMANUEL HEUSER. De província de São Pedro a estado do Rio Grande do Sul: censos do RS: 1803-1950. Porto Alegre: FEE, 1981.
HILL, Christopher. O eleito de Deus: Oliver Cromwell e a Revolução Inglesa. São Paulo: Companhia das Letras, 1988.

. Christopher. O mundo de ponta-cabeça: idéias radicais durante a Revolução Inglesa de 1640. São Paulo: Companhia das Letras, 1987.

INVENTÁRIO de José Ferreira Porto. Autuado em 1882. Inventários. Cartório de Órfãos e Ausentes. Rio Pardo, APERS, n. 111, 1882.

INVENTÁRIO de Mathias José Velho. Autuado em 8 de março de 1876. Inventários. Cartório de Órfãos e Ausentes. Rio Pardo, APERS, n. $803,1876$.

IOTTI, Luiza Horn (Org.). Imigração e colonização: legislação de 1747 a 1915. Porto Alegre: Assembleia Legislativa do Estado do Rio Grande do Sul; Caxias do Sul: Educs, 2001.

LINHARES, Maria Yedda. História agrária. In: CARDOSO, Ciro Flamarion; VAINFAS, Ronaldo (Org.). Domínios da História: ensaios de teoria e metodologia. 5. ed. Rio de Janeiro: Campus, 1997.

LINHARES, Maria Yedda Leite; SILVA, Francisco Carlos Teixeira. História da agricultura brasileira: combates e controvérsias. São Paulo: Brasiliense, 1981.

Terra prometida: uma história da questão agrária no Brasil. Rio de Janeiro: Campus, 1999.

MACEDO, Francisco Riopardense de. A arquitetura. In: RIO Grande do Sul terra e povo. 2. ed. Porto Alegre: Globo, 1969.

MARTINS, José de Souza. O cativeiro da terra. São Paulo: Hucitec, 1981.

MOTTA, Márcia Maria M. Nas fronteiras do poder: conflito e direito à terra no Brasil do século XIX. Rio de Janeiro: Vício de Leitura; Arquivo Público do Estado do Rio de Janeiro, 1998.

OFÍCIO do Juiz Comissário de Cruz Alta, Francisco José Alves Monteiro, ao Presidente da Província. 23/12/1867. AHRGS. Imigração, 
Terras e Colonização - Correspondências - Terras Públicas.1867. Maço 43 Caixa 23.

REGISTRO Paroquial de Terras. Livro de Registro de Terras da Parochia de Rio Pardo. 1854-1856. Rio Pardo, APERS, 1854-1856.

REZENDE, Mariana. Rio Pardo histórias e recordações. Rio Pardo: [S. n.], 1987.

RIO GRANDE DO SUL. Secretaria da Administração e dos Recursos Humanos. Departamento de Arquivo Público. Documentos da escravidão: inventários: o escravo deixado como herança / Coordenação Bruno Stelmach Pessi. - Porto Alegre: Companhia Rio-grandense de Artes Gráficas (CORAG), 2010.

SILVA, Francisco Carlos Teixeira; LINHARES, Maria Yedda L. Região e historia agrária. Estudos Históricos, Rio de Janeiro, v. 8, n. 15, 1995.

SPENNER, Bruna Vieira. Arquitetura, gado e cativo: estâncias pastoris em Rio Pardo no final do século XIX. Dissertação (Mestrado em Desenvolvimento Regional) - Universidade de Santa Cruz do Sul, Santa Cruz do Sul, 2013.

VIAL, Sandra Regina Martini. Propriedade da terra: análise sociojurídica. Porto Alegre: Livraria do Advogado, 2003.

VOGT, Olgário Paulo. Formação social e econômica da porção meridional do Vale do Rio Pardo. In: SILVEIRA, R. L. L.; VOGT, O. (Org.). Vale do Rio Pardo: (re)conhecendo a região. Santa Cruz do Sul: Edunisc, 2001. p. 69-122.

WASSERMAN, Cláudia. A formação do Estado Nacional na América Latina: as emancipações políticas e o intricado ordenamento dos novos países. In: (Coord.). História da América Latina: cinco séculos: temas e problemas. 2. ed. Porto Alegre: Ufrgs, 2000. p. 177-214.

ZARTH, Paulo Afonso. Do arcaico ao moderno: o Rio Grande do Sul agrário do século XIX. Ijuí: Unijuí, 2002. 